NASA Contractor Report 195357

AIAA-94-3310

\title{
Multiple Hollow Cathode Wear Testing for the Space Station Plasma Contactor
}

George C. Soulas

NYMA, Inc.

Engineering Services Division

Brook Park, Ohio

July 1994

Prepared for

Lewis Research Center

Under Contract NAS3-25266

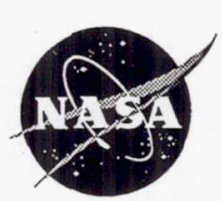

National Aeronautics and

Space Administration 


\title{
Multiple Hollow Cathode Wear Testing for the Space Station Plasma Contactor
}

\author{
George C. Soulas \\ NYMA, Inc. \\ NASA Lewis Research Center Group \\ Brook Park, $\mathrm{OH} 44142$
}

\begin{abstract}
A wear test of four hollow cathodes was conducted to resolve issues associated with the Space Station plasma contactor. The objectives of this test were to evaluate unit-to-unit dispersions, verify the transportability of contamination control protocols developed by the project, and to evaluate cathode contamination control and activation procedures to enable simplification of the gas feed system and heater power processor. These objectives were achieved by wear testing four cathodes concurrently to 2000 hours. Test results showed maximum unit-to-unit deviations for discharge voltages and cathode tip temperatures to be $\pm 3 \%$ and $\pm 2 \%$, respectively, of the nominal values. Cathodes utilizing contamination control procedures known to increase cathode lifetime showed no trends in their monitored parameters that would indicate a possible failure, demonstrating that contamination control procedures had been successfully transferred. Comparisons of cathodes utilizing and not utilizing a purifier or a simplified activation procedure showed similar behavior during wear testing and pre- and post-test performance characterizations. This behavior indicates that use of simplified cathode systems and procedures are consistent with long cathode lifetimes.
\end{abstract}

\section{Introduction}

A hollow cathode-based plasma contactor has been baselined for use on the Space Station to reduce station electrical charging. ${ }^{1}$ The plasma contactor provides a low impedance connection to space plasma via a plasma produced by an arc discharge. The operational requirements of the plasma contactor include an electron emission capability of up to $10 \mathrm{~A}$, a clamping voltage of $<20 \mathrm{~V}$, and a continuous operational life of 2 years, as well as overall system simplicity. This requires the hollow cathode of the plasma contactor to operate at currents as high as $10 \mathrm{~A}$ with low voltage dispersions and a lifetime of 17,500 hours using a simple xenon gas feed system and power processor. Other applications for the hollow cathode include ion thrusters, ${ }^{2}$ which utilize a discharge cathode for ion production and a neutralizer cathode for ion beam neutralization, and Hall effect thrusters, ${ }^{3}$ which utilize a single cathode for ion production and beam neutralization. Until recently, however, hollow cathodes operating on inert gases have suffered from short lifetimes, large dispersions with time, and large unit-to-unit dispersions. All of these issues must be resolved in order to achieve a reliable and repeatable plasma contactor design.

This paper is a declared work of the U.S. Government and is not subject to copyright protection in the United States.
Lifetimes on the order of 2 years and greater have been demonstrated with mercury propellant on ion thruster hollow cathodes. ${ }^{47}$ Dispersions with time were acceptable given the difficulties in maintaining a constant flow with mercury, however no publications were found with discussions of unit-to-unit dispersions. Use of mercury was discontinued in the early 1980's due to concerns about contamination of ground test facilities and spacecraft. As a result, inert gases were utilized. Unfortunately, cathode lifetimes with inert gas propellants were limited due in part to propellant impurities and feed system leaks which caused degradation of internal cathode surfaces. ${ }^{8}$

Many tests were conducted in excess of 1000 hours and at high currents ( $>1 \mathrm{~A}$ ) in an attempt to resolve these lifetime issues. ${ }^{8-12}$ Beattie, et al. ${ }^{9}$ conducted a 4350 hour cyclic lifetest of a $25 \mathrm{~cm}$ diameter xenon ion thruster. The main discharge and neutralizer hollow cathodes were operated at emission currents of $6.3 \mathrm{~A}$ and approximately $2.5 \mathrm{~A}$, respectively. During the first 700 hours, the ion thruster hollow cathodes experienced extreme erosion that required changes in cathode orifice dimensions and gas flows. Discharge voltage, ignition voltage, and cathode temperature data were not reported. Brophy and Garner ${ }^{10}$ conducted a 5024 hour hollow cathode lifetest at an emission current of 25 A. Maximum discharge voltage deviations were approximately $\pm 5 \mathrm{~V}$ from a nominal 
17.5 $\mathrm{V}$ and ignition voltages increased from a low of $18 \mathrm{~V}$ to $>900 \mathrm{~V}$ by the end of the test. The cathode orifice plate also experienced severe erosion with the orifice diameter increasing by $14 \%$ of its starting value. Kitamura, et al. ${ }^{11}$ conducted a cyclic test of a $14 \mathrm{~cm}$ diameter ion thruster that accumulated 1859 hours. Although few quantitative data were presented, the neutralizer had to be replaced 597 hours into testing due to erratic operation and the main discharge cathode experienced excessive erosion with maximum voltage deviations of $+6 \mathrm{~V} /-9 \mathrm{~V}$ from a nominal $35 \mathrm{~V}$. Shimada, et al. ${ }^{12}$ conducted endurance tests on 9 ion engine systems for periods of 2300 hours to over 9100 hours, and hollow cathode endurance tests on 6 hollow cathodes for 8000 hours. Results presented showed maximum voltage deviations between $\pm 4 \%$ to $\pm 33 \%$ of the nominal value. All voltage deviations were attributed, in part, to impurities in the xenon propellant. No discussion of unit-to-unit dispersions was presented.

The longest reported stable operation of a high current inert gas hollow cathode is an ongoing test conducted by Sarver-Verhey. ${ }^{8}$ This hollow cathode lifetest has accumulated $>10000$ hours of operation at an emission current of $12 \mathrm{~A}$ and a xenon flow of 0.41 $\mathrm{mg} / \mathrm{s}$. Maximum discharge and ignition voltage deviations have been $\pm 2.0 \mathrm{~V}$ of a nominal $12.9 \mathrm{~V}$ and $\pm 3.5 \mathrm{~V}$ of a nominal $41.6 \mathrm{~V}$, respectively. To date, this lifetest has successfully demonstrated both extended cathode lifetime capability and a control of dispersions with time. However, unit-to-unit dispersions have not yet been considered by this or any other work utilizing inert gases. Furthermore, the transportability of the contamination control procedures has not been demonstrated. The test of Reference 8 also utilizes a gas purifier that would increase gas feed system complexity, as well as requiring flight qualification of the component, and a cathode activation sequence that would require the heater power processor to have several set points.

To address these issues, a wear test of multiple xenon hollow cathodes was conducted. The objectives of this test were to evaluate unit-to-unit dispersions, verify the transportability of the contamination control protocols developed by Sarver-Verhey, ${ }^{8}$ and to evaluate cathode contamination control and activation procedures to simplify the gas feed system and heater power processor. These objectives were achieved by weartesting four cathodes concurrently to 2000 hour. All cathodes utilized the contamination control protocols in Reference 8 and were either operated with or without a purifier and a simplified activation procedure. The report will describe the facility, test hardware, and testing procedures. The test results of unit-to-unit dispersions and simplified contamination control methods will be presented and discussed.

\section{Apparatus}

The hollow cathode, shown in Fig. 1, consisted of a refractory metal tube with an cylindrical orifice plate welded to one end. The hole of the orifice plate was chamfered on the outer surface. All cathode orifice diameters were approximately $1.0 \mathrm{~mm}$. The cathode orifice dimension, though different from the plasma contactor design or that of Reference 8, was chosen on the basis of hardware availability. The cathode tube was coupled to the gas feed line with a compression fitting. An electron-emitting insert was fitted inside the cathode tube and its electrical leads were welded to the upstream end of the tube. The insert was a porous metallic tube impregnated with a compound to lower the surface work function. A refractory metal, sheathed heater was coiled about the downstream end of the cathode tube and was used for removing contaminants from the insert surface and bringing impregnant material to the insert surface (commonly known as activation), and for aiding in ignition. ${ }^{2}$ The heater was enclosed within a radiation shield to reduce radiated heat losses, similar to those used in Reference 13. This configuration allows the cathode to operate at low temperatures, low input powers, and high current densities $\left(10 \mathrm{~A} / \mathrm{cm}^{2}\right)$, resulting in high power efficiencies and extended lifetimes. This cathode design is similar to that used in Reference 8. A total of four hollow cathodes of this design were wear tested.

Each cathode emitted current to a separate anode. A schematic and photograph of a cathode-anode assembly are shown in Figs. 2 and 3, respectively. Each cathode utilized a $0.10 \mathrm{~m}$ square refractory metal anode that was mounted onto a threaded supporting rod and isolated from it with a ceramic electrical isolator. The supporting rod allowed the gap between cathode and anode to be adjusted. For this study, the cathodeanode distances were set to $2.2 \mathrm{~cm}$. All cathodes were isolated from tank ground with propellant isolators. Power to the heaters was provided by $10 \mathrm{~A}, 16 \mathrm{~V}$ direct current power supplies. Power for the discharges was provided by either a $10 \mathrm{~A}$ or a $20 \mathrm{~A}$, $55 \mathrm{~V}$ direct current power supplies. All electrical connections were made with 12 gauge wires that were welded to the cathode compression fittings and 
mechanically connected to the heaters and anodes. All cathode-anode assemblies and their respective power supplies were electrically isolated from each other and were not grounded.

A schematic of the gas feed systems is shown in Fig. 4. Two gas feed systems were used and each gas feed system supplied xenon gas to two hollow cathodes through separate gas lines. The gas feed systems utilized ultra-high vacuum components and were wrapped with heater tape to permit a bake-out. Flows were controlled manually with precision control valves and were monitored by flow meters. Each gas feed system utilized high purity xenon and was pressurized to $340 \mathrm{kPa}$. Cathodes with and without a purifier installed in its gas line were tested in each port. The cathodes with a purifier represented a configuration similar to that of Reference 8 .

A photograph of the facility is given in Fig. 5 . The facility used for the wear test was a $1 \mathrm{~m}$ diameter by $1.5 \mathrm{~m}$ long stainless steel tank with two $0.33 \mathrm{~m}$ diameter by $0.41 \mathrm{~m}$ long stainless steel ports that were isolated with pneumatic gate valves and were located at one end and to the side of the tank. Two cathodeanode assemblies and one gas feed system were mounted onto the flange of each port. Each pair of assemblies were separated with a $0.20 \mathrm{~m} \times 0.30 \mathrm{~m}$ stainless steel cathode shield, shown in Fig. 2. The facility was pumped by a $0.89 \mathrm{~m}$ diameter helium refrigerator cryopump horizontally mounted onto an end of the tank. The measured pumping speed of the cryopump was approximately $13000 \mathrm{~L} / \mathrm{s}$ of xenon. The base tank pressure was $5.3 \times 10^{-7} \mathrm{~Pa}$ and the tank pressure with gas flow was $4.6 \times 10^{-3} \mathrm{~Pa}$.

Parameters monitored throughout the wear test included discharge currents and voltages, cathode tip temperatures, mass flows, and pressures. These parameters were used to assess the condition of each cathode during testing. Discharge currents and voltages were measured with current transducers and voltage dividers, respectively. The AC components of these parameters were periodically monitored with 200 $\mathrm{MHz}$ digital oscilloscopes. Cathode tip temperatures were measured with Type $\mathrm{R}$ (platinum/platinum-13\% rhodium) thermocouples welded on the cathode tubes approximately $1.5 \mathrm{~mm}$ from the orifice plate, as shown in Fig. 1, and with optical pyrometers monitoring the orifice plate temperature at a position below the chamfer of the orifice. The emissivity correction for each pyrometer was set to 0.39 to account for the emissivity of the plate and the transmissivity of the quartz windows. Mass flows were measured by thermal mass flow meters. Tank pressure and port pressures, shown in Fig. 2, were measured with Bayard-Alpert ionization gauges corrected for the xenon gas. Other parameters monitored during gas feed system bake-outs and leak rate tests included gas feed system temperatures and pressures. These temperatures and pressures were measured with Type $\mathrm{K}$ (nickelchromium/nickel-aluminum) thermocouples and capacitance manometers, respectively.

A computerized data acquisition and control system was used to record data and to control two of the four discharge and heater power supply sets used for the wear test. A schematic of this system is shown in Fig. 6. Separate computers were used to control the power supplies and to acquire and record data. The control computer interfaced with the power supplies via a General Purpose Interface Bus (GPIB) coupled to a power supply controller. The acquisition computer interfaced to a 32 channel multiplexer and an analog-todigital converter via a GPIB. The multiplexer, which contained signal conditioners to electrically isolate and condition the incoming signals, was commanded to send its analog signals to the analog-to-digital converter. The converter then digitized the signals and sent them to the acquisition computer via the GPIB. The computer saved these data on an internal disk drive and also printed a hard copy. Recorded parameters included discharge currents and voltages, mass flows, cathode thermocouple temperatures, tank pressure, and elapsed time. The estimated accuracies of the measurements are listed in Table 1. Data for wear testing was acquired in 10 minute intervals. The facility terminated testing whenever the tank pressure was too high or if the gate valves were closed. Two strip chart recorders were also used to continuously monitor discharge currents and voltages, pyrometric temperatures, and port pressures.

\section{Test Procedures and Operating Conditions}

A number of procedures developed by SarverVerhey $^{8}$ were conducted before initiating a cathode discharge. These procedures included evacuations, bake-outs, and leak rate tests of the gas feed systems and cathode activations. Evacuations and bake-outs were conducted to remove trapped air or moisture whenever the gas feed systems were exposed to ambient air. All internal surfaces of the gas feed systems would be evacuated and then baked-out using heater tape wrapped around the external system components. Leak rate tests were conducted whenever the gas feed systems were altered in any way, including 
after a xenon bottle replacement, to identify any possible leaks that may introduce contaminants into the flow path of the xenon gas. The test involved isolating the evacuated gas feed systems and monitoring the rate of pressure rise with capacitance manometers. The results were used to characterize feed system integrity.

Activation procedures were conducted whenever the hollow cathodes were exposed to ambient air in order to remove contaminants from the cathode insert. Two activation procedures were used. The first was that used in Reference 8 and the second was a simplified version. The simplified version had two steps removed in the activation procedure.

The propellant flow meters were calibrated before and after wear testing with a bubble flow calibrator to determine a volumetric flow. The flows reported in this test were converted to a mass flow.

At the completion of testing, gas samples were taken from each gas feed line to quantify the impurity levels. The outlets of the gas lines, shown in Fig. 4, were connected to the inlet of a gas chromatograph for an in-situ measurement of impurity levels. These results were used to quantify the impurity levels in the xenon gas.

The cathode operating conditions are listed in Table 2. The cathodes were operated concurrently in a steady-state mode throughout the 2000 hour test. This duration was considered adequate ${ }^{14}$ to expose any adverse impacts of contamination or improper activation effects. The cathode designation number and letter indicated the port and gas feed line, respectively, onto which the cathode was mounted. The mass flows were those required for stable discharge operation. The cathode gas feed lines with purifiers represented a configuration similar to that of Reference 8 so that the transportability of cathode contamination control procedures could be evaluated. The results from cathode gas feed lines with and without purifiers were used to evaluate the utility of a purifier in an attempt to simplify the flight gas feed system. One cathode was operated with a simplified activation process in an attempt to simplify power processor requirements. Finally, the wear test results of four hollow cathodes was used to evaluate unit-to-unit dispersions.

\section{Test Results}

\section{Effects of Operating Multiple Hollow Cathodes Concurrently \\ Before initiating the wear test, the effects of operating multiple hollow cathodes concurrently in}

close proximity were examined. Three separate effects were investigated. The first was the influence of an increased local pressure due to additional flow from adjacent cathodes that were not ignited. Cathode $1 \mathrm{~A}$ was operated at $10 \mathrm{~A}$ and $0.91 \mathrm{mg} / \mathrm{s}$ which produced a discharge voltage of $8.53 \mathrm{~V}$ in a regime of operation referred to as "spot" mode, ${ }^{14}$ similar to that of the wear test. Propellant flow was introduced into the remaining cathodes at flows as high as $0.93 \mathrm{mg} / \mathrm{s}$ per cathode. The port pressure subsequently rose from $7.0 \times 10^{-3} \mathrm{~Pa}$ to $1.6 \times 10^{-2} \mathrm{~Pa}$, a factor of 2.3 increase. The discharge voltage of cathode $1 \mathrm{~A}$ decreased to $8.39 \mathrm{~V}$, a $1.6 \%$ reduction. At operating conditions where the cathodes are in the "plume" mode, a factor of 2.6 pressure increase results in $14 \%$ reduction in discharge voltage. The decrease in discharge voltage with an increasing local pressure for both cases may have been due to a decrease in the anode fall voltage, which has been documented in past studies. ${ }^{15,16}$

The second effect studied was the operation of two discharges concurrently. With cathode $1 \mathrm{~A}$ operating at $5 \mathrm{~A}$ and $0.33 \mathrm{mg} / \mathrm{s}$, cathode $1 \mathrm{~B}$ was ignited and operated at $0.33 \mathrm{mg} / \mathrm{s}$ and various discharge currents. The power supplies of each cathode were electrically isolated from each other and from ground. The results showed that at similar operating conditions, there is no detectable change in the discharge voltage and the $\mathrm{AC}$ components of the discharge currents and voltages of cathode 1A. However, when cathode 1B was operated at a low flow condition where the peak-to-peak $\mathrm{AC}$ components of the discharge current and voltage were $9.4 \mathrm{~A}$ and $9.1 \mathrm{~V}$, respectively, the peak-to-peak $\mathrm{AC}$ voltage component of cathode $1 \mathrm{~A}$ increased from $2.0 \mathrm{~V}$ to $6.7 \mathrm{~V}$ while the change in the $\mathrm{AC}$ current component was negligible. The frequencies of the $\mathrm{AC}$ voltage components of both cathodes were also identical. This phenomenon was independent of whether or not cathode $1 \mathrm{~A}$ was operated in "spot" or "plume" modes of operation. This indicated the existence of "crosstalk" in the discharge voltages of two cathodes running concurrently. This effect was possibly caused by the capacitors and $1 \mathrm{M} \Omega$ impedance used for isolating the discharge power supplies and oscilloscope voltage inputs, respectively, from ground. Although these electrical isolating techniques isolated the DC component of the discharges from ground, the $\mathrm{AC}$ components could still be detected. The AC voltage component of cathode 1B discharge was detected in the voltage signal of cathode $1 \mathrm{~A}$ because a voltage probe was coupled to cathode $1 \mathrm{~A}$. Since current probes were used to monitor discharge current, the $\mathrm{AC}$ component of cathode $1 \mathrm{~A}$ showed no change. 
The third effect examined was the influence of adjacent discharges on an ignition. This was accomplished by comparing the ignition voltages of cathodes ignited with and without an adjacent discharge. Without adjacent discharges, ignition voltages of all cathodes were $20-22 \mathrm{~V}$. With adjacent discharges, ignition voltages were $17-20 \mathrm{~V}$. The differences were within $3 \mathrm{~V}$. At the end of the wear test, differences were within $1 \mathrm{~V}$.

\section{Wear Test Results}

The wear test chronology is given in Table 3 . The test experienced 7 interruptions, typically the result of xenon bottle replacements and/or cryopump system failures. Discharge power supply $2 \mathrm{~B}$ failed 716 hours into testing and was replaced at test hour 820. As a result, cathode $2 \mathrm{~B}$ was not operated between test hour 716 and test hour 820 and was therefore tested for approximately 100 hours more than cathodes $1 \mathrm{~A}, 1 \mathrm{~B}$, and $2 \mathrm{~A}$. Cathodes $1 \mathrm{~A}, 1 \mathrm{~B}$, and $2 \mathrm{~A}$ accumulated 2015 hours of operation while cathode $2 \mathrm{~B}$ accumulated 2005 hours.

Discharge voltages for all cathodes throughout the wear test are shown in Fig. 7. The oscillations in the discharge voltages with test time were due to the daily variations in mass flow. These variations were caused by fluctuations in gas feed system pressure due to daily temperature changes. Maximum and average mass flow deviations were $+0.133 /-.093 \mathrm{mg} / \mathrm{s}$ and \pm 0.027 $\mathrm{mg} / \mathrm{s}$, respectively, from the nominal $0.82 \mathrm{mg} / \mathrm{s}$ setting. Discharge voltages decreased by approximately $0.2-0.4$ $\mathrm{V}$ about 820 hours into testing for unknown reasons. However, no cathodes showed any long-term trends, such as an increasing voltage throughout the test, that would be indicative of a failure. Wear test results are shown in Table 4. The mean discharge voltages were 8.27-8.54 $\mathrm{V}$ to within a maximum range of $1.47 \mathrm{~V}$ for all cathodes. The largest contributor to these deviations were the large fluctuations of mass flow. The uncertainty associated with the voltage measurements at these nominal values was $\pm 0.03 \mathrm{~V}$.

The $\mathrm{AC}$ components of the discharge current and voltage were measured periodically throughout the test. The peak-to-peak magnitudes were typically $0.07 \mathrm{~A}$ and $0.55 \mathrm{~V}$ for the discharge current and voltage, respectively. The peak-to-peak magnitude of the voltage was largely due to voltage spikes that occurred in 8.4 millisecond intervals. These spikes were caused by the inability of the 20 A power supplies to maintain voltage stability at these operating conditions when connected to the dynamic plasma loads. Peak-to-peak $\mathrm{AC}$ components of the discharge current and voltage were not seen to exceed $0.12 \mathrm{~A}$ and $0.8 \mathrm{~V}$, respectively, throughout the test.

Ignition voltages for all cathodes are shown in Fig. 8. Ignitions were conducted sequentially so that three of the four cathodes were ignited with adjacent discharges. Ignitions were performed by increasing the voltage of the cathode discharge power supply until a discharge occurred. Ignition voltages were $<22 \mathrm{~V}$ throughout the test. Mean ignition voltages, listed in Table 4, were $16.6-17.4 \mathrm{~V}$ to within a maximum range of $7.0 \mathrm{~V}$ for all cathodes.

Cathode thermocouple and pyrometric temperatures throughout the wear test are shown in Figs. 9 and 10, respectively. Thermocouple and pyrometric temperatures revealed that following an ignition, the cathode temperature decreased or increased with time to an equilibrium state. It is speculated that impregnant coverage over the insert was not complete for the decreasing temperature case or was excessive for the increasing temperature case, but that coverage reached the same equilibrium condition with time. Pyrometric temperatures were $50-100{ }^{\circ} \mathrm{C}$ higher than the thermocouple measurements due to the different locations of the temperature measurements and possible inaccuracy of the emissivity correction. Pyrometric results, however, were useful as a relative measure to confirm thermocouple measurements. The increase in the pyrometric temperature of cathode $1 \mathrm{~A}$ between test hours 1660 and 1923 was due to the pyrometer being moved. There were no long-term trends that would indicate a possible failure in any cathode, such as an increasing temperature. Results of the thermocouple measurements are listed in Table 4. Mean temperatures were $1049-1109^{\circ} \mathrm{C}$ to within a maximum range of $77^{\circ} \mathrm{C}$ for all cathodes. The uncertainty of the thermocouple measurement was $\pm 3{ }^{\circ} \mathrm{C}$.

Results of unit-to-unit dispersions are listed in Table 5. Maximum cathode-to-cathode deviations in discharge voltage, ignition voltage, and cathode thermocouple temperature were $\pm 5.1 \%, \pm 16 \%$, and $\pm 3.5 \%$, respectively, of the respective mean values for all cathodes. As before, discharge voltage dispersions were largely due to large mass flow variations as a result of daily gas feed system pressure fluctuations. Temperature dispersions were due, in part, to a varying thermocouple locations on different cathodes.

\section{Performance Characteristics}

The performance of each cathode was characterized before and after the wear test. These performance tests included current-voltage and current-cathode tip temperature (as measured by the thermocouples) 
characteristics. Pre- and post-test results are shown in Figs. 11 and 12, respectively, for current-voltage characteristics and in Figs. 13 and 14, respectively, for current-cathode tip temperature characteristics. Comparisons of pre- and post-test results show that the discharge voltages and cathode tip temperatures generally decreased after the wear test. Discharge voltage decreases ranged from $0.42-2.35 \mathrm{~V}$. Cathode tip temperature dispersions varied from $14{ }^{\circ} \mathrm{C}$ to 66 ${ }^{\circ} \mathrm{C}$. These changes in performance were likely due to improved impregnant coverage of the insert surface with time, resulting in a lower surface work function and decreased discharge voltages and cathode tip temperatures.

A comparison of pre- and post-test unit-to-unit dispersions in the performance characteristics showed that maximum deviations generally decreased after the wear test. Pre-test cathode-to-cathode deviations in discharge voltage and cathode tip temperature for a given discharge current were as high as $\pm 0.99 \mathrm{~V}$ and $\pm 31{ }^{\circ} \mathrm{C}$, respectively, while post-test results were $\pm 0.25 \mathrm{~V}$ and $\pm 25^{\circ} \mathrm{C}$, respectively. The decrease in post-test maximum deviations was likely a result of a more uniform impregnant coverage of the insert surfaces for all cathodes.

\section{Post-Test Cathode Examination and Gas Analysis}

After the completion of the wear test and the posttest performance characterizations, all cathodes were examined in-situ and removed for photomicrographs of the orifice plates and a destructive examination of the cathode interior. The in-situ examination revealed that very little had changed in the appearance of the cathodes. Pre- and post-test photographs of cathode $2 \mathrm{~A}$, which are typical of all cathodes tested, are shown in Fig. 15. After testing, the machining marks on the orifice plate and in the chamfer were slightly visible and ion bombardment was noticeable. All corners in the chamfers were, however, sharp and all cathode orifice diameters showed no change except for cathode $1 \mathrm{~A}$ which increased by $3 \%$, as listed in Table 6 . Photomicrographs showed small white powder-like deposits, approximately $0.03-0.05 \mathrm{~mm}$ in diameter, intermittently along the orifice channel of all cathodes. These deposits were likely impregnant material that evaporated from the insert during testing and absorbed water upon exposure to atmosphere. Photomicrography up to 20X magnification indicated no large material deposition on either the orifice channel or the orifice plate. Destructive examinations of the cathode interiors are ongoing and results are pending.

The xenon gas exiting each gas feed line was analyzed with a gas chromatograph to measure levels of oxygen, moisture, carbon monoxide, carbon dioxide, and total hydrocarbons. These impurities are known to react with the impregnant compound and porous metal of the insert, as well as the refractory metal orifice channel, to produce adverse affects in cathode performance. The results show all impurities to be $<$ $10 \mathrm{ppm}$ for all gas feed lines. There were no differences in impurity levels for gas lines with or without a purifier, however the estimated impurity levels were below the accuracy of the gas chromatograph.

\section{Discussion}

The interactive effects of operating multiple hollow cathodes concurrently were insignificant for this test. Although an increase in the local pressure resulted in a decreasing discharge voltage, discharge voltage reductions due to increased local pressures were approximately $2 \%$ of the nominal value. This was because all cathodes were operated in the "spot" mode where voltage sensitivities to pressure are small. ${ }^{15}$ Furthermore, peak-to-peak AC components of the discharge current and voltage were $<1.2 \%$ and $<$ $9.5 \%$, respectively, of their nominal values, therefore "cross-talk" was minimized. Adjacent discharges also had little effect on ignition voltages.

Cathodes $1 \mathrm{~A}$ and $2 \mathrm{~A}$, which represented a gas feed system configuration similar to that of Reference 8, showed no trends in their wear test discharge voltages, ignition voltages, and cathode tip temperatures that would indicate a possible failure. Furthermore, maximum deviations in discharge voltage and cathode thermocouple temperature were less than the $\pm 2 \mathrm{~V}$ and $\pm 40{ }^{\circ} \mathrm{C}$, respectively, in Reference 8 during the first 2000 hours of operation. Although a comparison of pre- and post-test performance characteristics showed decreases in discharge voltage and cathode tube temperature by the end of the wear test, possibly, caused by improved impregnant coverage of the insert, this was not seen to adversely affect cathode longevity. The orifice channels and plates showed no large depositions that would be indicative of xenon impurities reacting with cathode material. These results showed that the contamination control procedures developed by Sarver-Verhey ${ }^{8}$ were successfully transferred to this test.

Results from comparisons of cathodes $1 \mathrm{~A}$ and $2 \mathrm{~A}$ to cathode $2 \mathrm{~B}$ were used to evaluate the option of purifier elimination. Gas analysis results lacked the 
accuracy to discern impurity levels of gas lines with or without purifiers so that quantifying these levels was not possible. The discharge voltages, ignition voltages, and cathode tip temperatures of cathodes $1 \mathrm{~A}, 2 \mathrm{~A}$, and $2 \mathrm{~B}$ behaved similarly throughout the wear test with the maximum deviations in these parameters for cathode $2 B$ typically less than those of cathodes $1 \mathrm{~A}$ and $2 \mathrm{~A}$. A comparison of pre- and post-test performance characterizations for these cathodes also showed decreases in the parameters of cathode $2 \mathrm{~B}$ to generally be less than those of cathodes $1 \mathrm{~A}$ and $2 \mathrm{~A}$. The condition of the orifice plate and channel of cathode $2 B$ was also very similar to those of cathodes $1 \mathrm{~A}$ and $2 \mathrm{~A}$, with no visible indication of large surface depositions with the use of photomicrography up to $20 \mathrm{X}$ magnification. Therefore, use of a purifier for discharge durations of $\leq 2000$ hours is not required. An analysis of the ongoing cathode destructive examination results is required in order to extrapolate purifier utility for durations beyond 2000 hours.

The activation process was evaluated by comparing the results of cathodes $1 \mathrm{~A}$ and $2 \mathrm{~A}$ to those of cathode 1B. The lack of a purifier for cathode $1 \mathrm{~B}$ will not bias results since, as shown before, lack of a purifier has no deleterious affects on cathode performance to 2000 hours. Discharge voltages, ignition voltages, and cathode tip temperatures of cathodes $1 \mathrm{~A}, 2 \mathrm{~A}$, and $1 \mathrm{~B}$ behaved similarly throughout the wear test with the maximum deviations of cathode $1 \mathrm{~B}$ typically less than those of cathodes $1 \mathrm{~A}$ and $2 \mathrm{~A}$. A comparison of preand post-test performance characterizations for these cathodes also showed decreases in discharge voltages for cathode $1 \mathrm{~B}$ to be similar to those of cathodes $1 \mathrm{~A}$ and $2 \mathrm{~A}$. The condition of the orifice plate and channel of cathode $1 \mathrm{~B}$ was also very similar to those of cathodes $1 \mathrm{~A}$ and $2 \mathrm{~A}$, with no indication of large surface depositions from photomicrography up to $20 \mathrm{X}$ magnification. The simplified activation process was therefore adequate for discharge operations $\leq 2000$ hours. Destructive cathode examination results are required to extrapolate these results for extended durations.

Unit-to-unit dispersions were evaluated by comparing the test results of all cathodes. Although the gas feed lines of cathodes $1 \mathrm{~B}$ and $2 \mathrm{~B}$ did not utilize purifiers and the activation process of cathode $1 \mathrm{~B}$ was simplified, comparisons of all cathodes are justified since neither the lack of a purifier nor usage of the simplified activation process adversely affected the cathode performance to 2000 hours. Wear test results showed maximum unit-to-unit deviations in discharge voltages, ignition voltages, and cathode tip temperatures to be $\pm 5.1 \%, \pm 16 \%$, and $\pm 3.5 \%$, respectively, of the respective mean values. Wear test discharge voltage deviations were mainly due to large xenon flow variations while cathode temperature deviations were due, in part, to varying thermocouple locations on each cathode. Pre- and post-test performance deviations were found to be less than those of the wear test since xenon flow variation effects could be controlled. Post-test results showed dispersions of discharge voltage and cathode temperature to be $\pm 3 \%$ and $\pm 2 \%$, respectively, of the nominal values.

\section{Conclusions}

A wear test of four xenon hollow cathodes was conducted for 2000 hours. The objectives of the test were to verify the transportability of the contamination control protocols developed by Sarver-Verhey ${ }^{8}$, to evaluate cathode contamination control and activation procedures to simplify the gas feed system and heater power processor, and to evaluate unit-to-unit dispersions. The effects of operating multiple hollow cathodes concurrently were found to be insignificant for this test. Discharge voltage reductions due to increased local pressures were approximately $2 \%$ of the nominal value, and peak-to-peak discharge current and voltage noises were $<1.2 \%$ and $<9.5 \%$, respectively, so that "cross-talk" was minimized. Cathodes with purifiers, which represented a configuration similar to that of Reference 8, showed no trends in their monitored parameters that would indicate a possible failure and maximum deviations in discharge voltage and cathode thermocouple temperature were less those of Reference 8 during the first 2000 hours of operation. This demonstrated that contamination control procedures had been successfully transferred. Comparisons of cathodes utilizing and not utilizing a purifier and different activation procedures showed similar behavior in wear test results, pre- and post-test performance characterizations, and post-test cathode examination results. Therefore, lack of a purifier or usage of simplified activation processes for discharge durations of $\leq 2000$ hours are satisfactory. An analysis of the cathode destructive examination results is required in order to extrapolate beyond 2000 hours. Comparisons of all cathodes showed maximum unit-tounit deviations for discharge voltages and cathode tip temperatures to be $\pm 3 \%$ and $\pm 2 \%$, respectively, of the nominal values. 


\section{References}

${ }^{1}$ Patterson, M. J., Hamley, J. A., Sarmiento, C. J., Manzella, D. H., Sarver-Verhey, T., Soulas, G. C., and Nelson, A., "Plasma Contactor Development for Space Station," International Electric Propulsion Conference Paper 93-246, September 1993.

${ }^{2}$ Anon., "30-Centimeter Ion Thruster Subsystem Design Manual," NASA TM-79191, June 1979.

${ }^{3}$ Sankovic, J., Hamley, J., and Haag, T., "Performance Evaluation of the Russian SPT-100 Thruster at NASA LeRC," International Electric Propulsion Conference Paper 93-094, September 1993.

${ }^{4}$ Bechtel, R. T., Trump, G. E., and James, E. J., "Results of the Mission Profile Life Test, " AIAA Paper 82-1905, November 1982.

${ }^{5}$ Manteneiks, M. A., "Hg Ion Thruster Component Testing," NASA TM-79287, October-November 1979.

${ }^{6}$ Nakanishi, S., "A 15,000-Hour Cyclic Endurance Test of an 8-cm Diameter Mercury Bombardment Ion Thruster," AIAA Paper 76-1022, November 1976.

${ }^{7}$ Collett, C. R. and Poeschel, R. L., "A 10,000

Hour Endurance Test of a 700 Series $30-\mathrm{cm}$ Engineering Model Thruster," AIAA Paper 76-1019, November 1976.

${ }^{8}$ Sarver-Verhey, T. R., "Continuing Life Test of a Xenon Hollow Cathode for a Space Plasma Contactor," AIAA Paper 94-3312, June 1994.

${ }^{9}$ Beattie, J. R., Matossian, J.N., and Robson, R.R., "Status of Xenon Ion Propulsion Technology," AIAA Paper 87-1007, May 1987.

${ }^{10}$ Brophy, J. and Garner, C., "A 5,000 Hour Xenon Hollow Cathode Life Test," AIAA Paper 912122, June 1991.

${ }^{11}$ Kitamura, S., Miyazaki, K., and Hayakawa, Y., "Cyclic Test of a $14 \mathrm{~cm}$ Diameter Ring-Cusp Xenon Ion Thruster," AIAA Paper 92-3146, July 1992.

${ }^{12}$ Shimada, S., Satoh, K., Gotoh, Y., Nishida, E., Noro, T., Takegahara, H., Nakamaru, K., and Nagano, H., "Ion Thruster Endurance Test Using Development Model Thruster for ETS-VI," International Electric Propulsion Conference Paper 93169, September 1993.

${ }^{13}$ Soulas, G. C., "Status of Hollow Cathode Heater Development for the Space Station Plasma Contactor," AIAA Paper 94-3310, June 1994.

${ }^{14}$ Sarver-Verhey, T. R., Private Communication, NYMA, Inc., Brook Park, OH, October 1993.

${ }^{15}$ Kaufman, H. R., "Technology of ElectronBombardment Ion Thrusters, " Advances in Electronics and Electron Physics, Vol. 36, Academic Press, New
York, 1974, pp. 265-373.

${ }^{16}$ Soulas, G. C. and Myers, R. M., "Mechanisms of Anode Power Deposition in a Low Pressure Free Burning Arc," International Electric Propulsion Conference Paper 93-194, September 1993. 
Table 1 Estimated Accuracy of Parameter Measurements

\begin{tabular}{cc}
\hline Parameter & Accuracy \\
\hline Discharge Current, A & $\pm 1.7 \%$ of reading \\
Discharge Voltage, $\mathrm{V}$ & $\pm 0.4 \%$ of reading \\
Thermocouple Temperature, ${ }^{\circ} \mathrm{C}$ & $\pm 3{ }^{\circ} \mathrm{C}$ \\
Pyrometric Temperature, ${ }^{\circ} \mathrm{C}$ & $\pm 6{ }^{\circ} \mathrm{C}$ \\
Mass Flow, mg/s & $2 \%$ of reading \\
Pressure, Pa & $\pm 25 \%$ of reading \\
\hline \hline
\end{tabular}

Table 2 Wear Test Operating Conditions

\begin{tabular}{ccccc}
\hline \hline Cathode & $\begin{array}{c}\text { Discharge } \\
\text { Current, A }\end{array}$ & $\begin{array}{c}\text { Xenon Flow, } \\
\mathrm{mg} / \mathrm{s}\end{array}$ & Purifier & Activation Process \\
\hline 1A & 10.0 & 0.82 & Yes & See Reference 8 \\
1B & 10.0 & 0.82 & No & Simplified \\
2A & 10.0 & 0.82 & Yes & See Reference 8 \\
2B & 10.0 & 0.82 & No & See Reference 8 \\
\hline
\end{tabular}

Table 3 Wear Test Chronology

\begin{tabular}{|c|c|c|c|}
\hline Termination & Test Time, $\mathrm{h}$ & Cause of Interruption & $\begin{array}{l}\text { Cathodes } \\
\text { Interrupted }\end{array}$ \\
\hline- & 0 & Wear Test Initiation & NA \\
\hline 1 & 316 & $\begin{array}{l}\text { Xenon Bottle Replacement/Facility } \\
\text { Failure }\end{array}$ & $1 \mathrm{~A}, 1 \mathrm{~B}, 2 \mathrm{~A}, 2 \mathrm{~B}$ \\
\hline 2 & 342 & Facility Failure $^{b}$ & $1 \mathrm{~A}, 1 \mathrm{~B}, 2 \mathrm{~A}, 2 \mathrm{~B}$ \\
\hline 3 & 716 & Power Supply Failure & $2 \mathrm{~B}$ \\
\hline 4 & 820 & Power Supply Replacement & $1 \mathrm{~A}, 1 \mathrm{~B}, 2 \mathrm{~A}, 2 \mathrm{~B}$ \\
\hline 5 & 1113 & $\begin{array}{c}\text { Xenon Bottle Replacement/Facility } \\
\text { Failure }\end{array}$ & $1 \mathrm{~A}, 1 \mathrm{~B}, 2 \mathrm{~A}, 2 \mathrm{~B}$ \\
\hline 6 & 1324 & Facility Failure $^{\mathrm{a}}$ & $1 \mathrm{~A}, 1 \mathrm{~B}, 2 \mathrm{~A}, 2 \mathrm{~B}$ \\
\hline 7 & 1923 & $\begin{array}{c}\text { Xenon Bottle Replacement/Facility } \\
\text { Failure }\end{array}$ & $1 \mathrm{~A}, 1 \mathrm{~B}, 2 \mathrm{~A}, 2 \mathrm{~B}$ \\
\hline 8 & 2015 & Wear Test Completion & $1 \mathrm{~A}, 1 \mathrm{~B}, 2 \mathrm{~A}$ \\
\hline 9 & 2109 & Wear Test Completion & $2 \mathrm{~B}$ \\
\hline
\end{tabular}


Table 4 Wear Test Results

\begin{tabular}{|c|c|c|c|c|c|c|c|c|}
\hline \multirow{2}{*}{ Parameter } & \multicolumn{4}{|c|}{ Mean Values } & \multicolumn{4}{|c|}{ Maximum Deviations } \\
\hline & $1 \mathrm{~A}$ & $1 \mathrm{~B}$ & $2 \mathrm{~A}$ & $2 \mathrm{~B}$ & $1 \mathrm{~A}$ & $1 \mathrm{~B}$ & $2 \mathrm{~A}$ & $2 \mathrm{~B}$ \\
\hline $\begin{array}{c}\text { Discharge Voltage, } \\
\text { V }\end{array}$ & 8.54 & 8.39 & 8.31 & 8.27 & $\begin{array}{l}+0.61 \\
-0.71\end{array}$ & $\begin{array}{l}+0.48 \\
-0.63\end{array}$ & $\begin{array}{l}+0.94 \\
-0.53\end{array}$ & $\begin{array}{l}+.90 \\
-.54\end{array}$ \\
\hline $\begin{array}{c}\text { Ignition Voltage, } \\
\text { V }\end{array}$ & 17.4 & 16.5 & 17.5 & 16.6 & $\begin{array}{l}+4.6 \\
-2.4\end{array}$ & $\begin{array}{l}+2.0 \\
-1.5\end{array}$ & $\begin{array}{l}+2.5 \\
-1.6\end{array}$ & $\begin{array}{l}+3.4 \\
-1.6\end{array}$ \\
\hline $\begin{array}{l}\text { Thermocouple } \\
\text { Temp., }{ }^{\circ} \mathrm{C}\end{array}$ & 1109 & 1083 & 1049 & 1112 & $\begin{array}{l}+29 \\
-35\end{array}$ & $\begin{array}{l}+33 \\
-44\end{array}$ & $\begin{array}{l}+60 \\
-17\end{array}$ & $\begin{array}{l}+24 \\
-28\end{array}$ \\
\hline
\end{tabular}

Table 5 Wear Test Unit-To-Unit Results

\begin{tabular}{cccc}
\hline \hline Parameter & $\begin{array}{c}\text { Mean } \\
\text { Values }\end{array}$ & $\begin{array}{c}\text { Maximum } \\
\text { Deviations }\end{array}$ & $\begin{array}{c}\text { Average } \\
\text { Deviations }\end{array}$ \\
\hline $\begin{array}{c}\text { Discharge Voltage, } \\
\text { V }\end{array}$ & 8.38 & \pm 0.43 & \pm 0.12 \\
$\begin{array}{c}\text { Ignition Voltage, } \\
\text { V }\end{array}$ & 17.0 & \pm 2.8 & \pm 0.8 \\
$\begin{array}{c}\text { Cathode Tip Temp., } \\
{ }^{\circ} \mathrm{C}\end{array}$ & 1088 & \pm 48 & \pm 12 \\
\hline \hline
\end{tabular}

Table 6 Pre- and Post-Test Orifice Diameters

\begin{tabular}{cccc}
\hline Cathode & $\begin{array}{c}\text { Pre-Test Diameter, } \\
\text { mm }\end{array}$ & $\begin{array}{c}\text { Post-Test Diameter, } \\
\text { mm }\end{array}$ & $\%$ Change \\
\hline 1A & 0.98 & 1.00 & +3 \\
1B & 1.00 & 1.00 & 0 \\
2A & 0.98 & 0.98 & 0 \\
2B & 1.00 & 1.00 & 0 \\
\hline
\end{tabular}




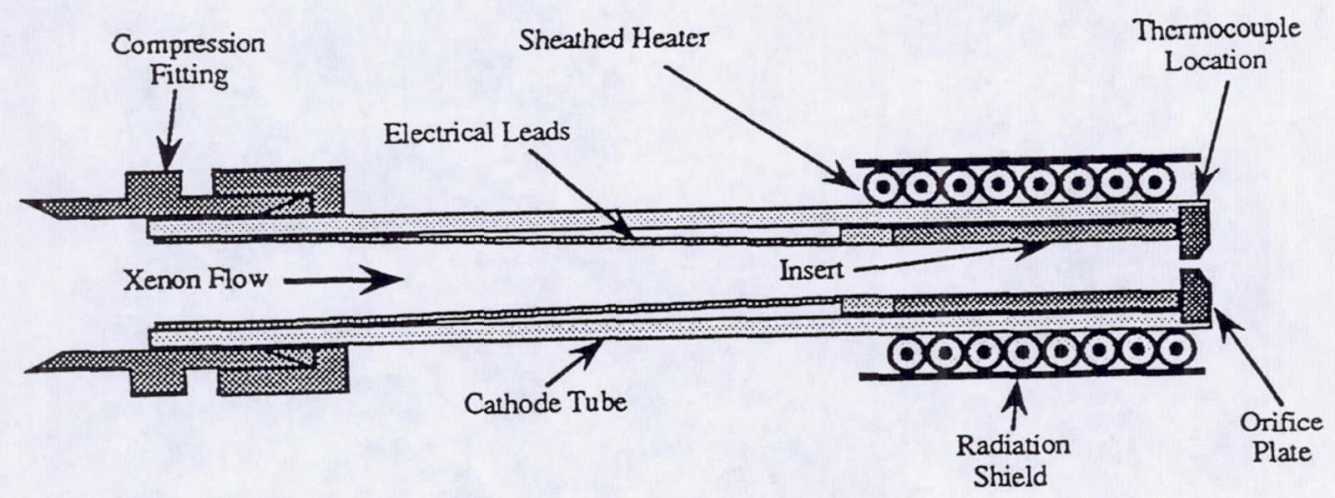

Fig. 1 Drawing of a wear test hollow cathode.

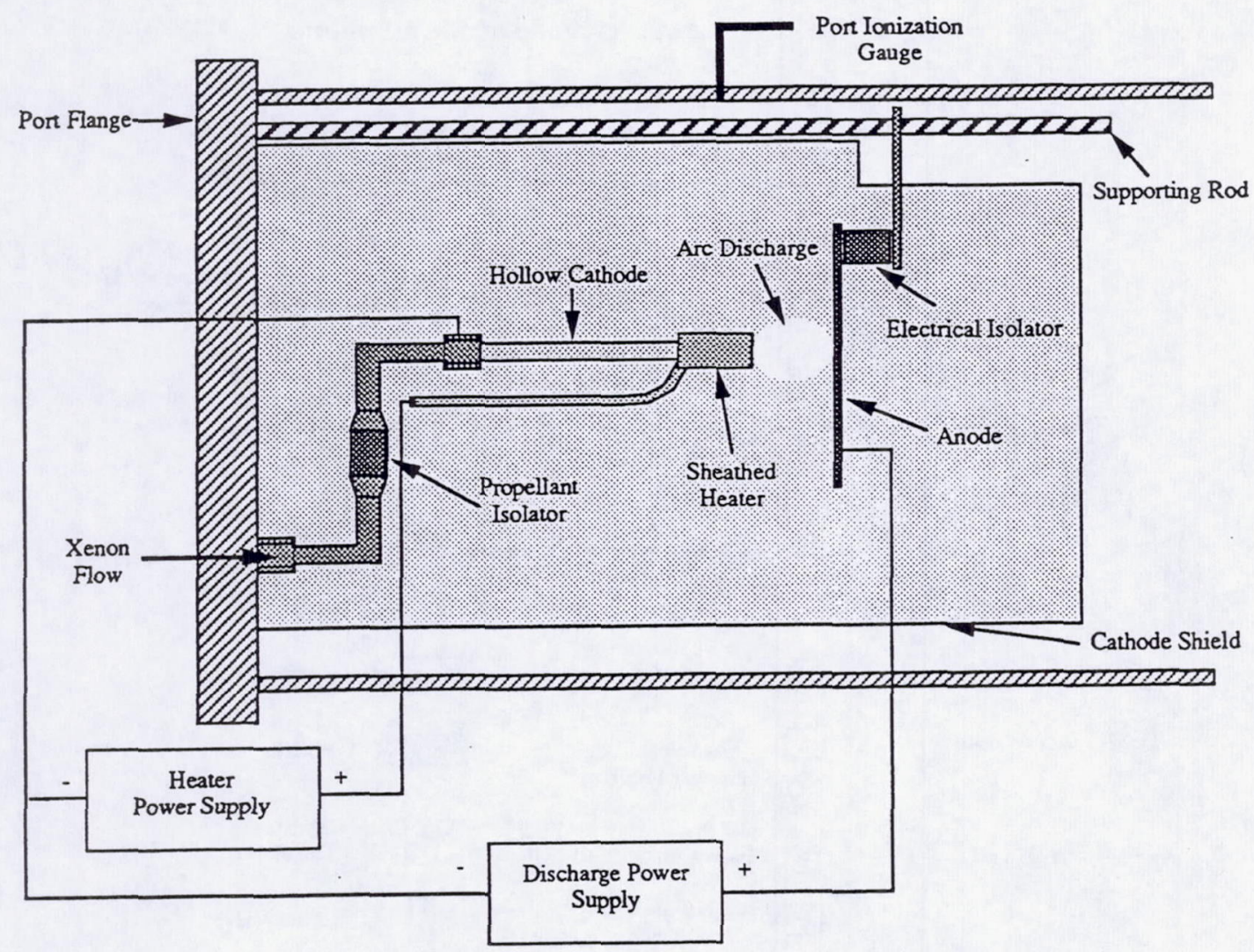

Fig. 2 Schematic of a cathode-anode assembly. 


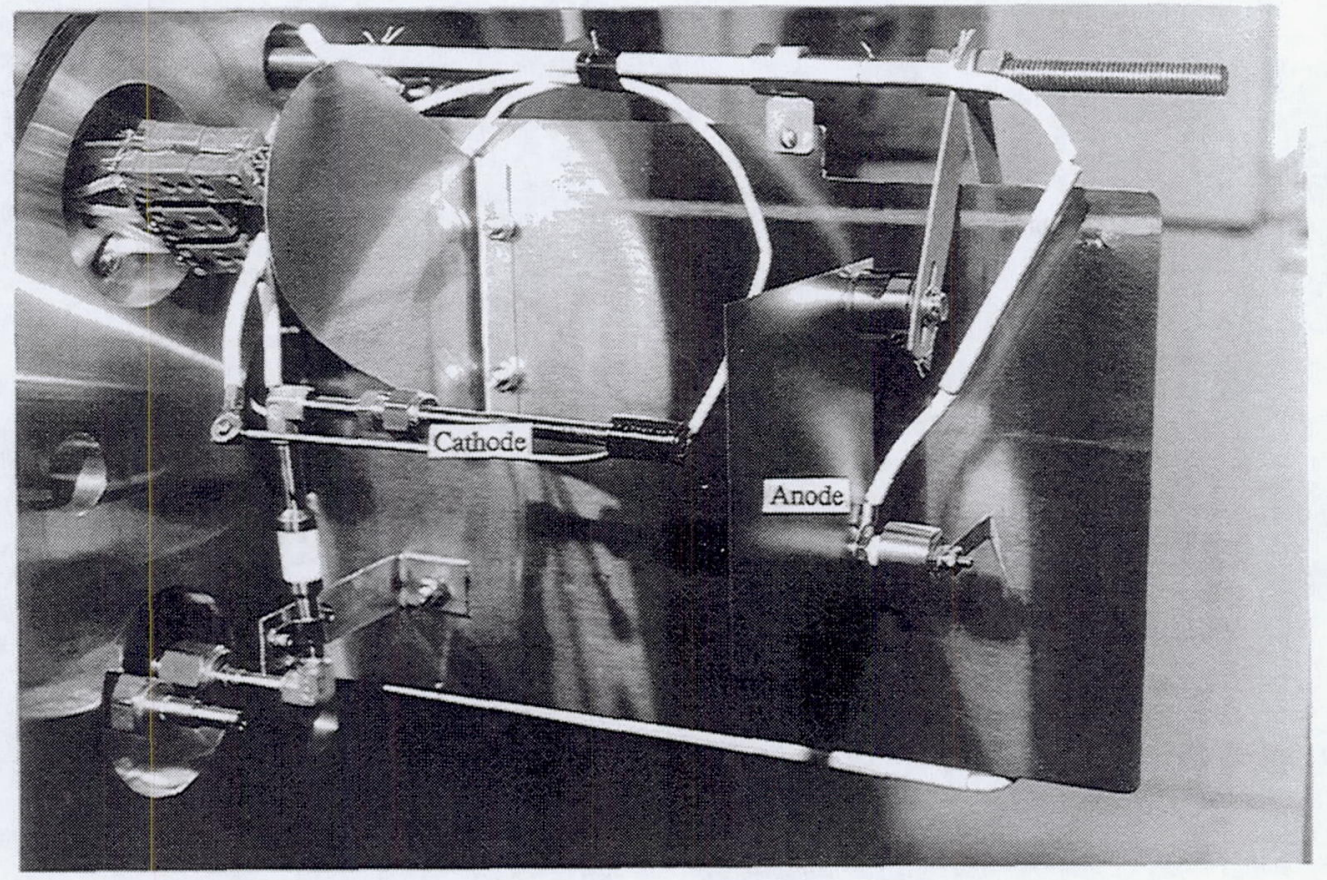

Fig. 3 Photograph of a cathode-anode assembly.

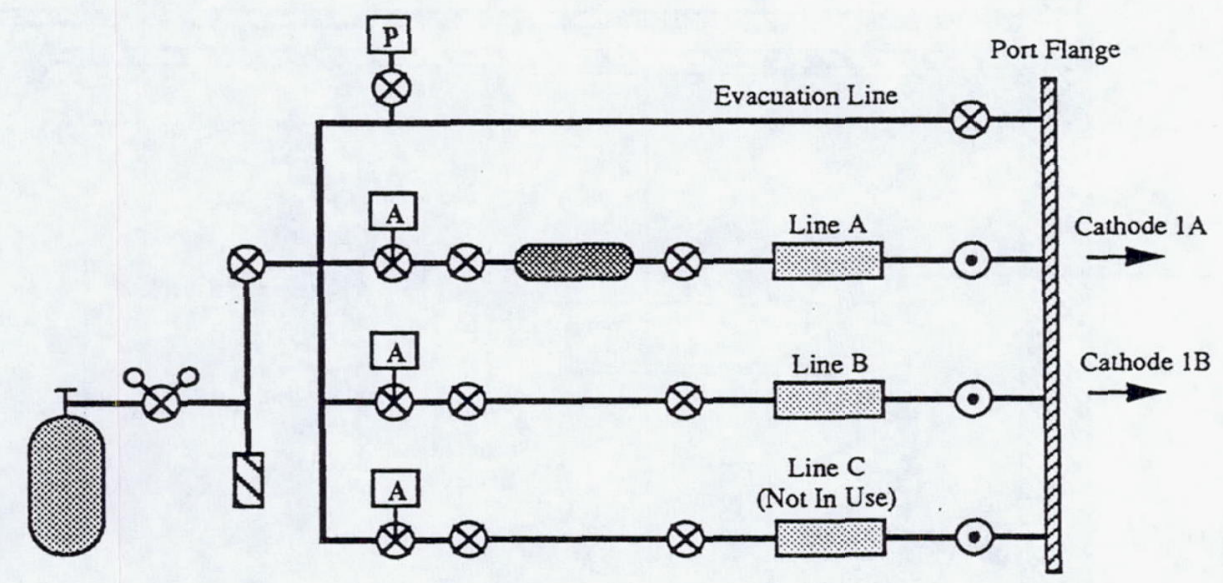

I

$\bigotimes$ Shut-off Valve

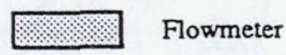

Xenon Botule

A $\begin{gathered}\text { Air-Actuated } \\ \text { Shut-off Valve }\end{gathered}$

Tubing

- Flow Control Valve

80 Pressure

P. Capacitance

$\triangle \quad$ Relief Valve

Fig. 4 Schematic of Port 1 gas feed system. Port 2 gas feed system was identical. 


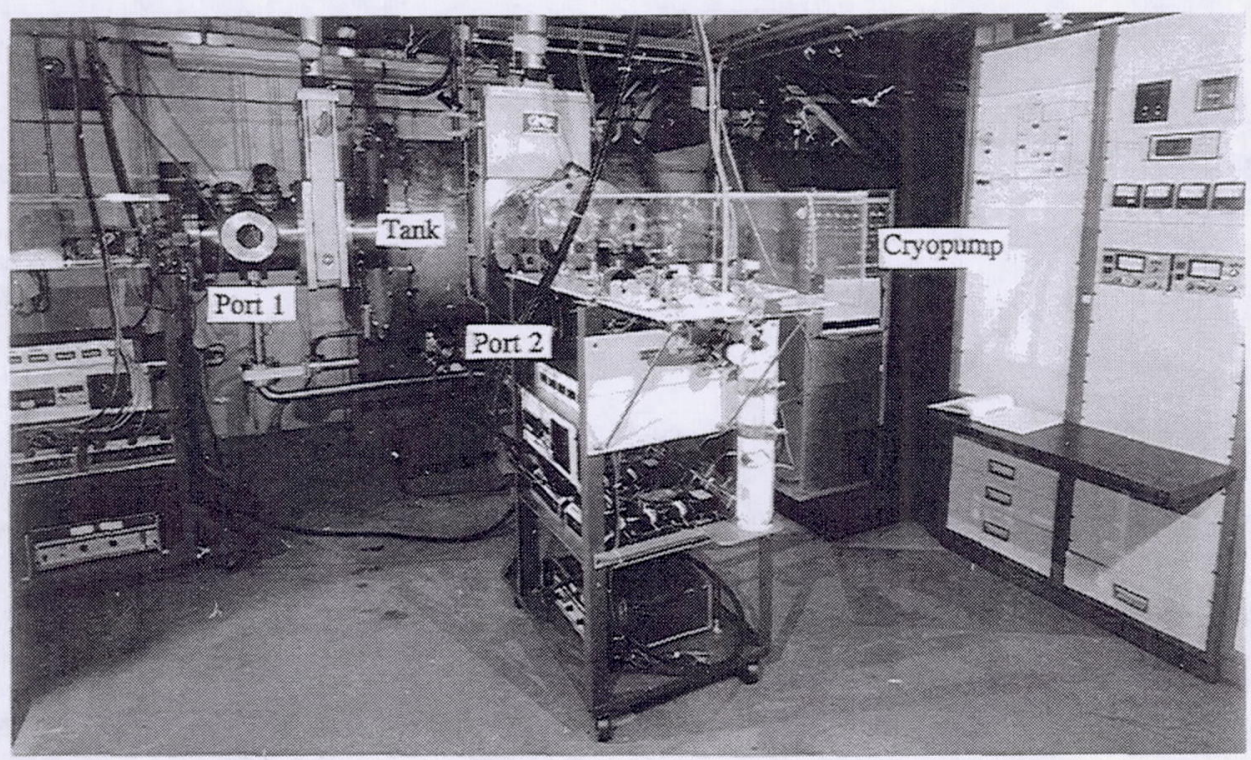

Fig. 5 Photograph of the vacuum facility.

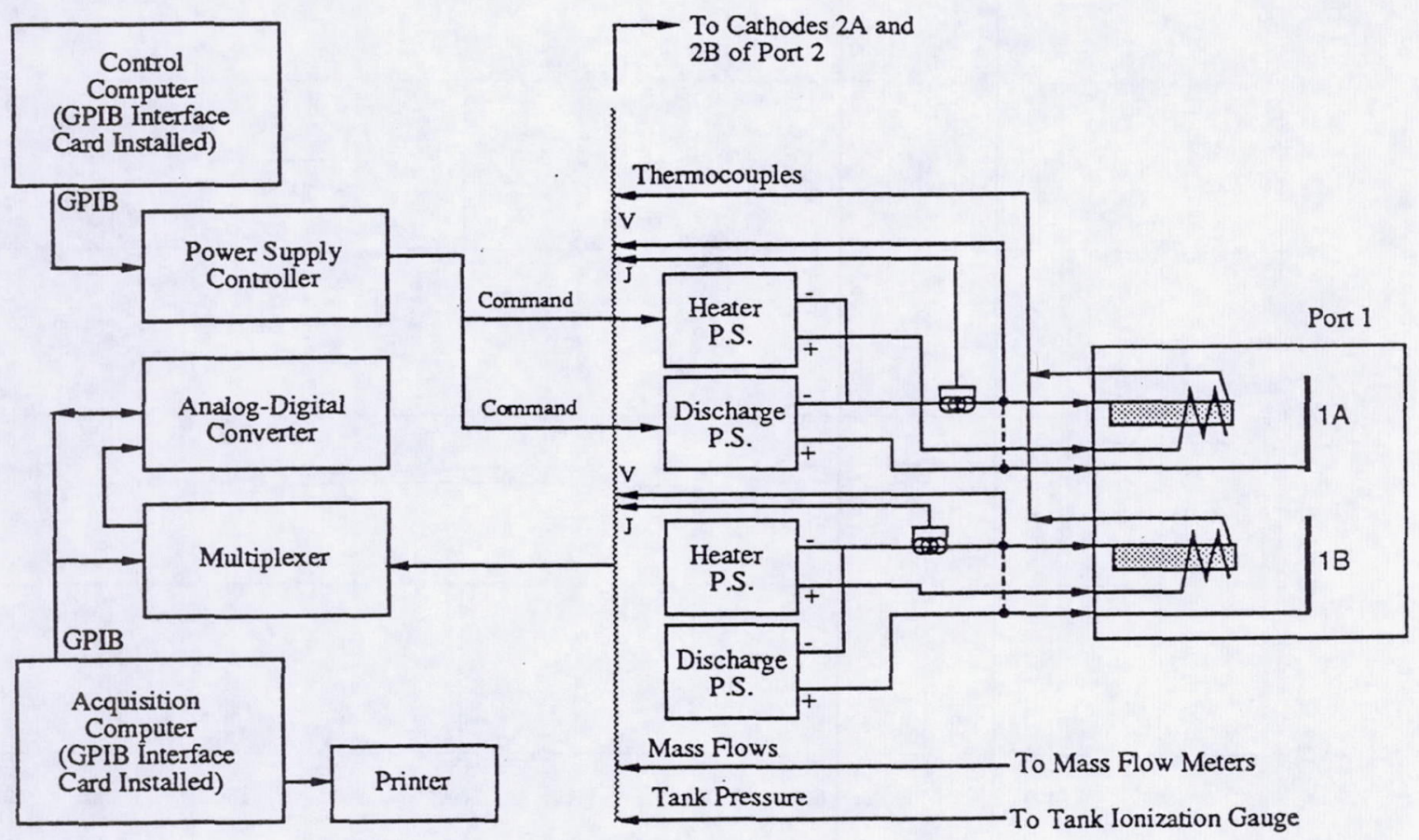

Fig. 6 Schematic of the data acquisition and control system. Only one port and no strip chart recorders are shown. All power supplies were isolated from each other and from ground. 


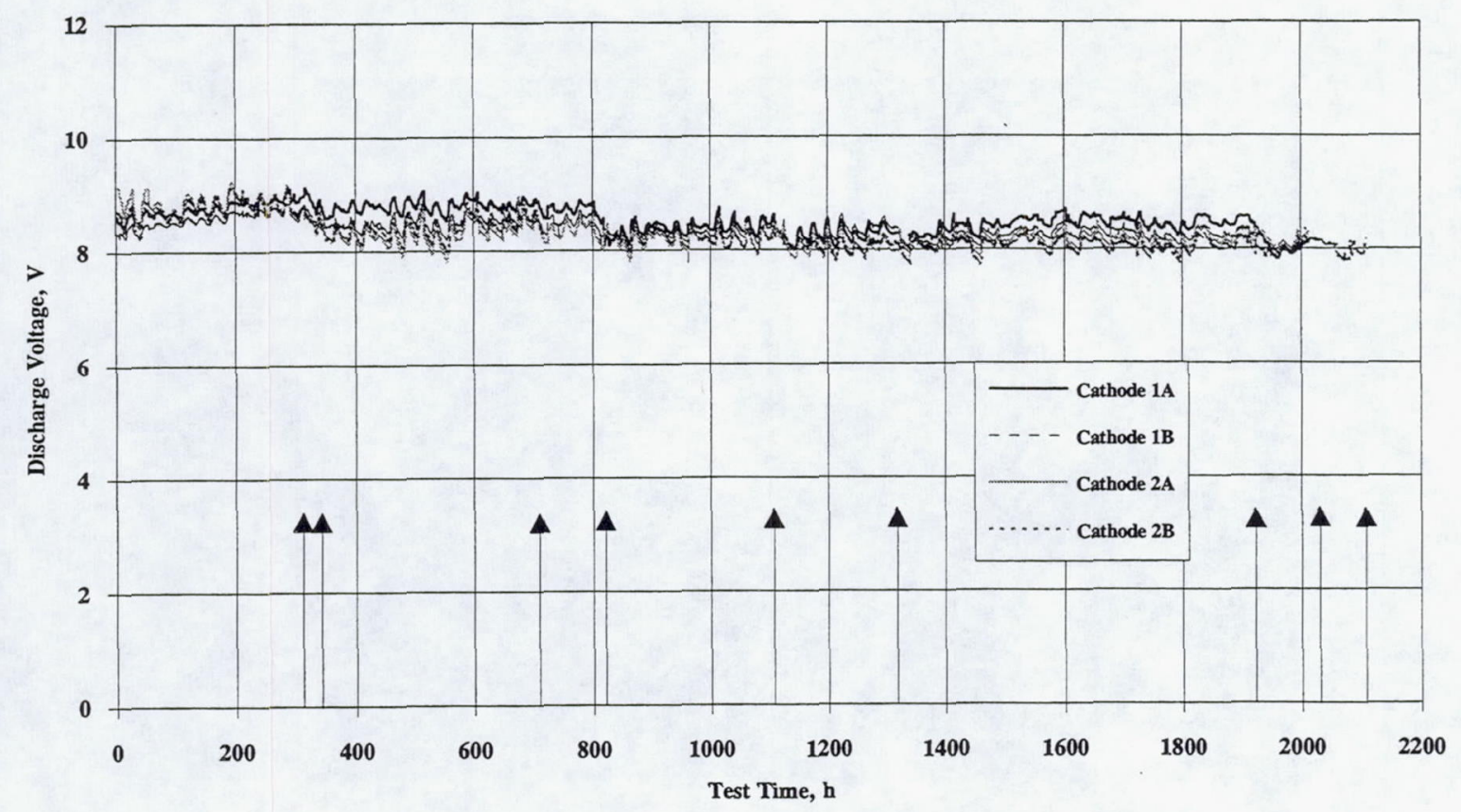

Fig. 7 Discharge voltage throughout wear test for all cathodes. Arrows indicate test interruptions.

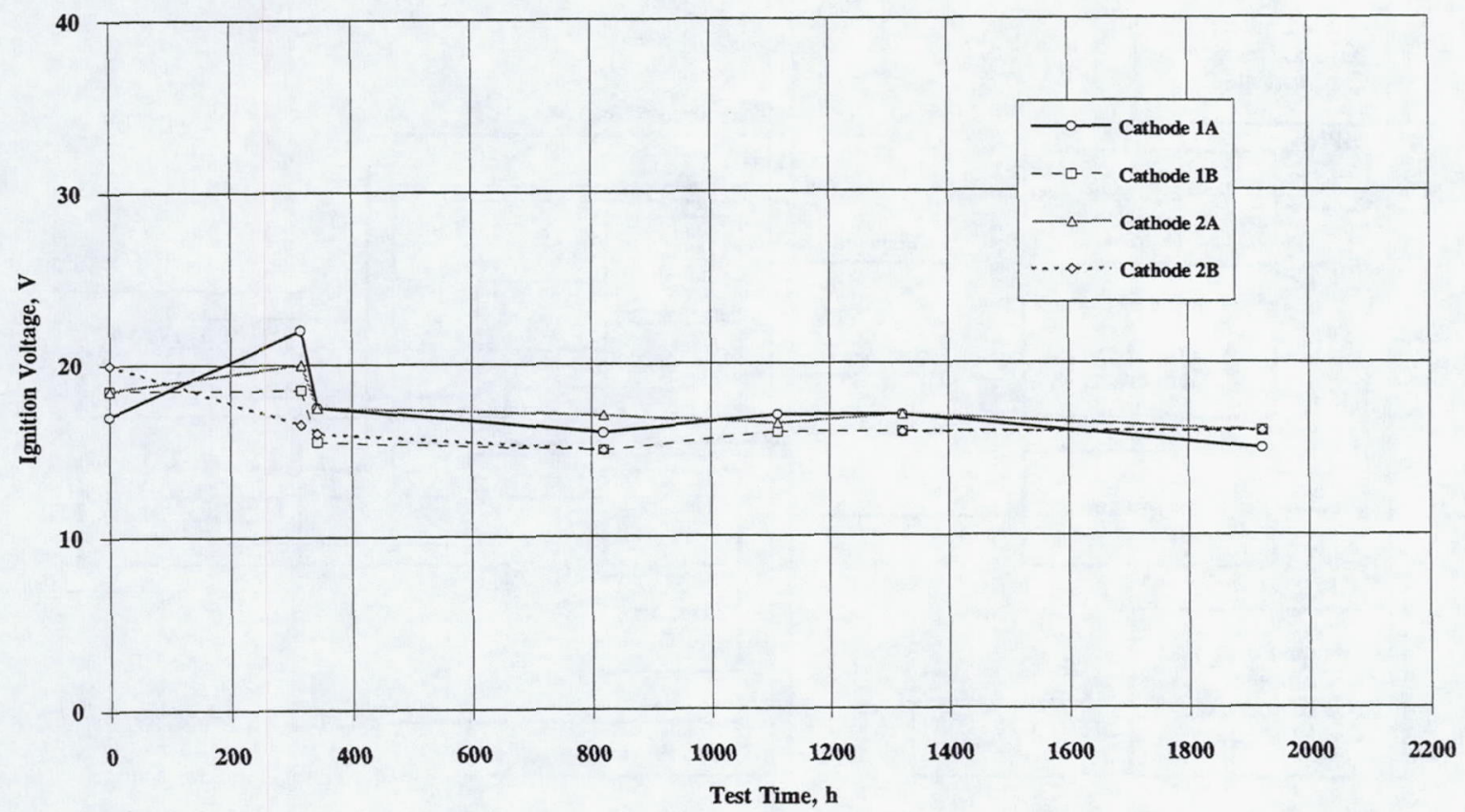

Fig. 8 Hollow cathode ignition voltages throughout the wear test. 


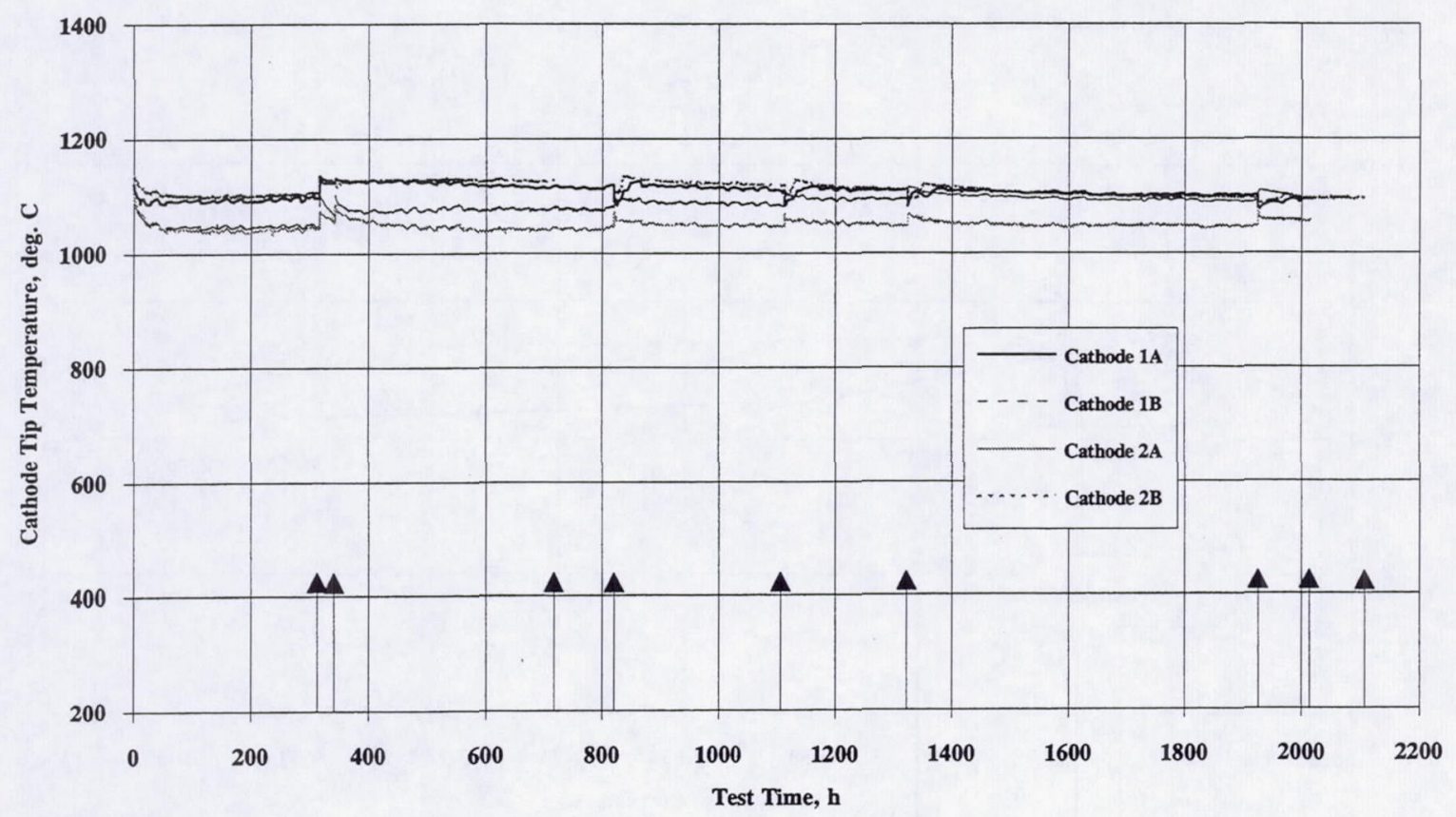

Fig. 9 Cathode tip thermocouple temperatures throughout the wear test for all cathodes. Arrows indicate test interruptions.

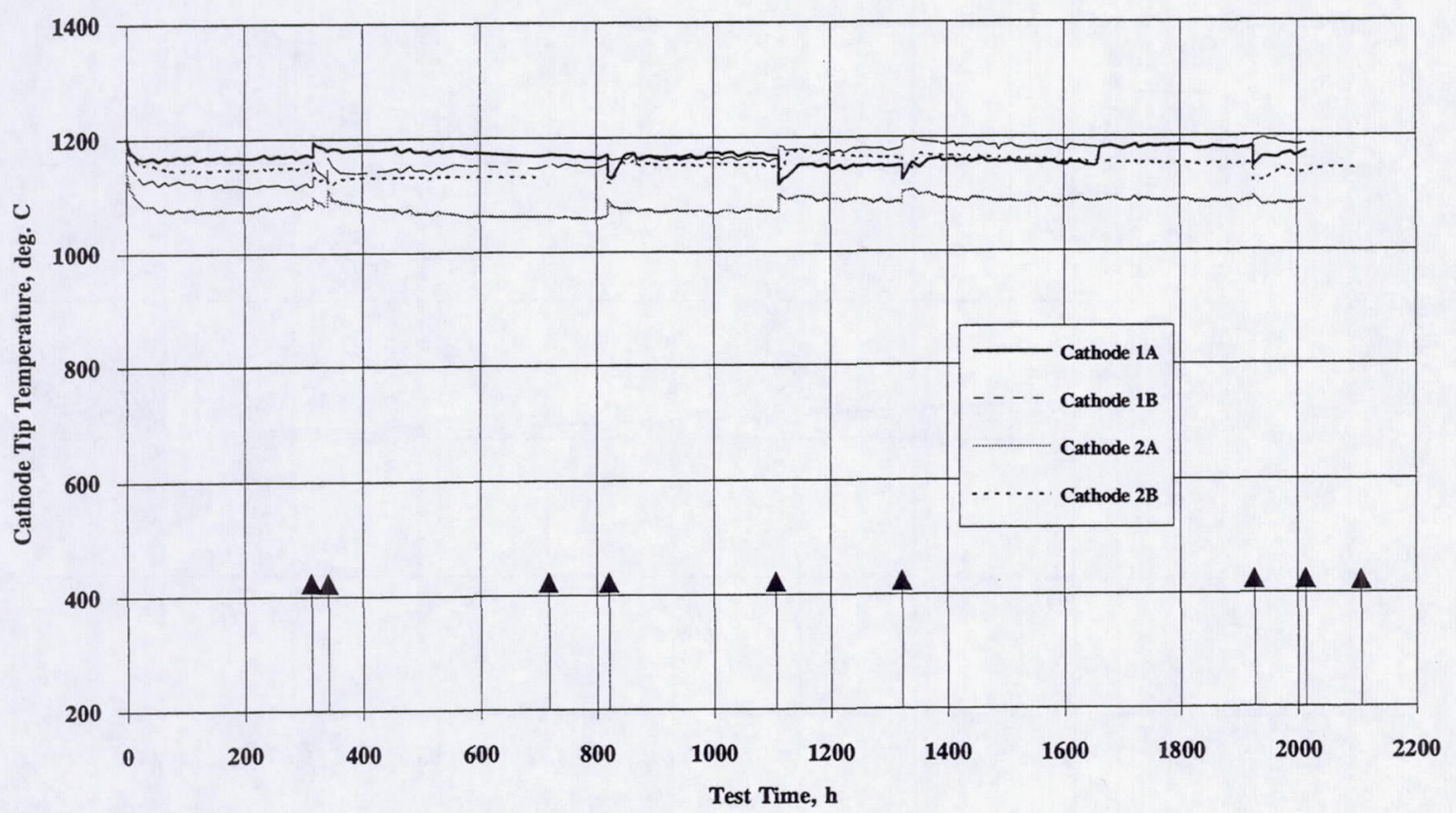

Fig. 10 Cathode tip pyrometric temperatures throughout the wear test for all cathodes. Arrows indicate test interruptions. 


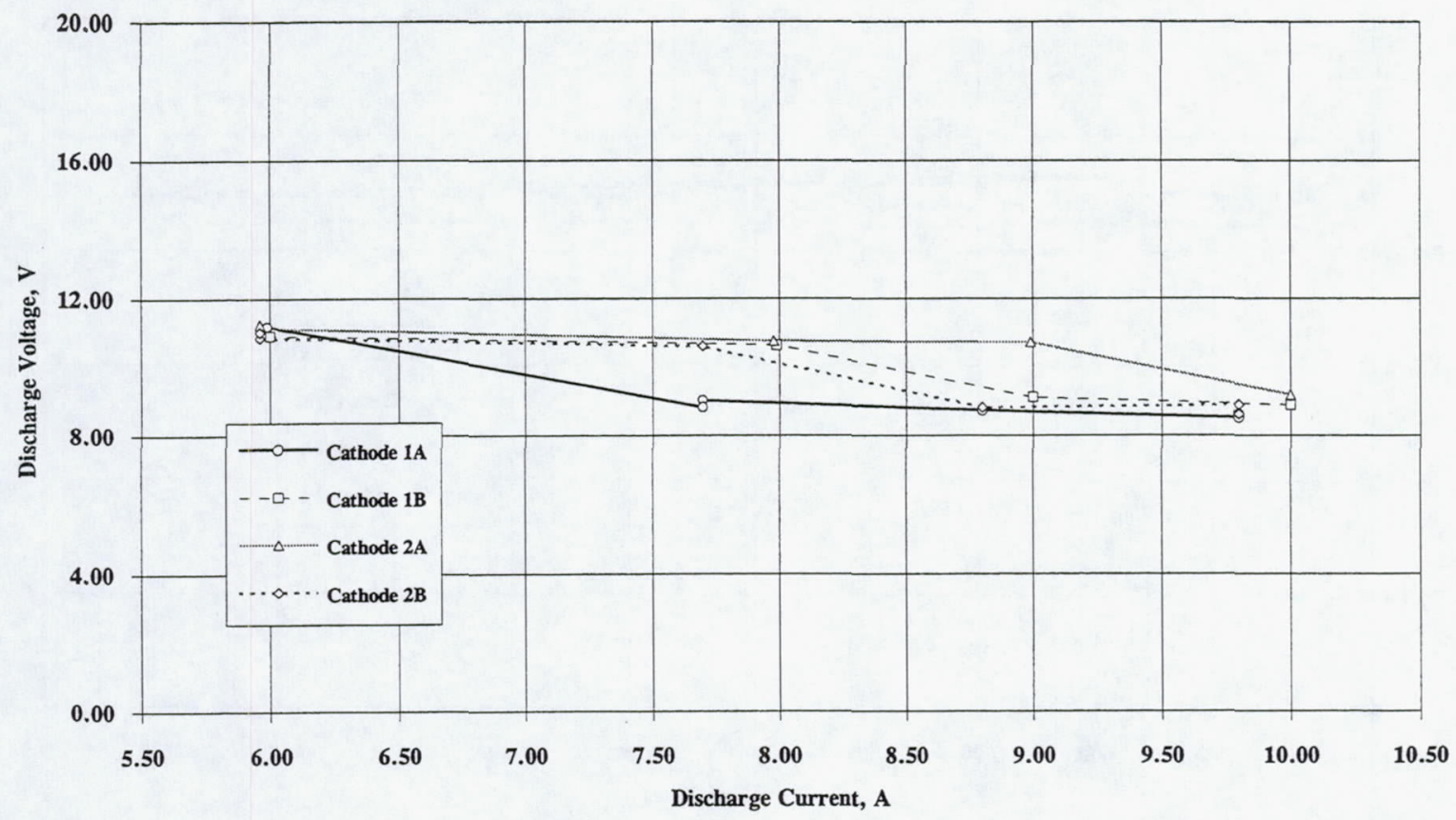

Fig. 11 Pre-test current-voltage characteristics for all cathodes at $0.9 \mathrm{mg} / \mathrm{s}$ except at $6 \mathrm{~A}$ where the flow is $1.0 \mathrm{mg} / \mathrm{s}$.

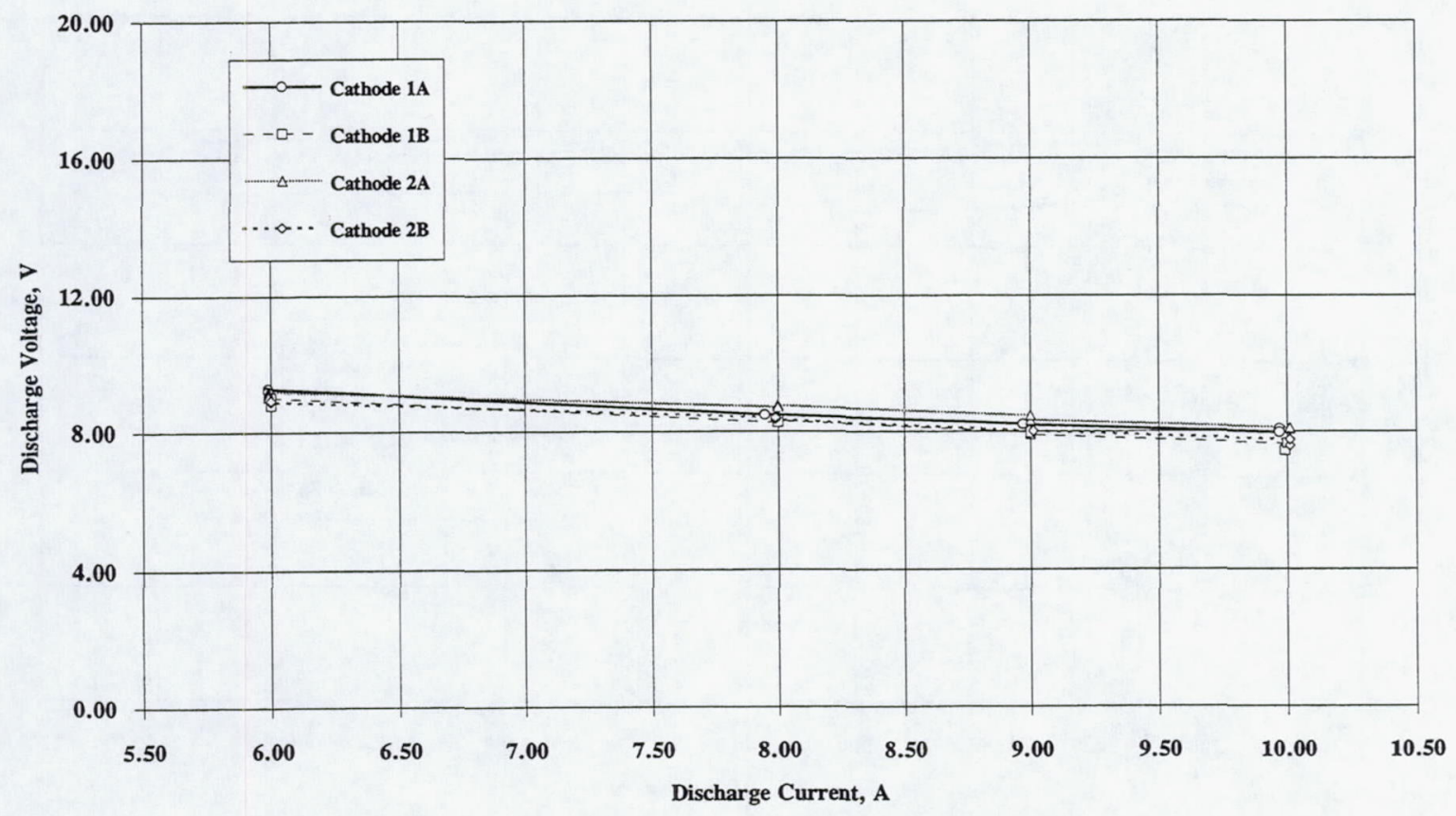

Fig. 12 Post-test current-voltage characteristics for all cathodes at $0.9 \mathrm{mg} / \mathrm{s}$ except at $6 \mathrm{~A}$ where the flow is $1.0 \mathrm{mg} / \mathrm{s}$. 


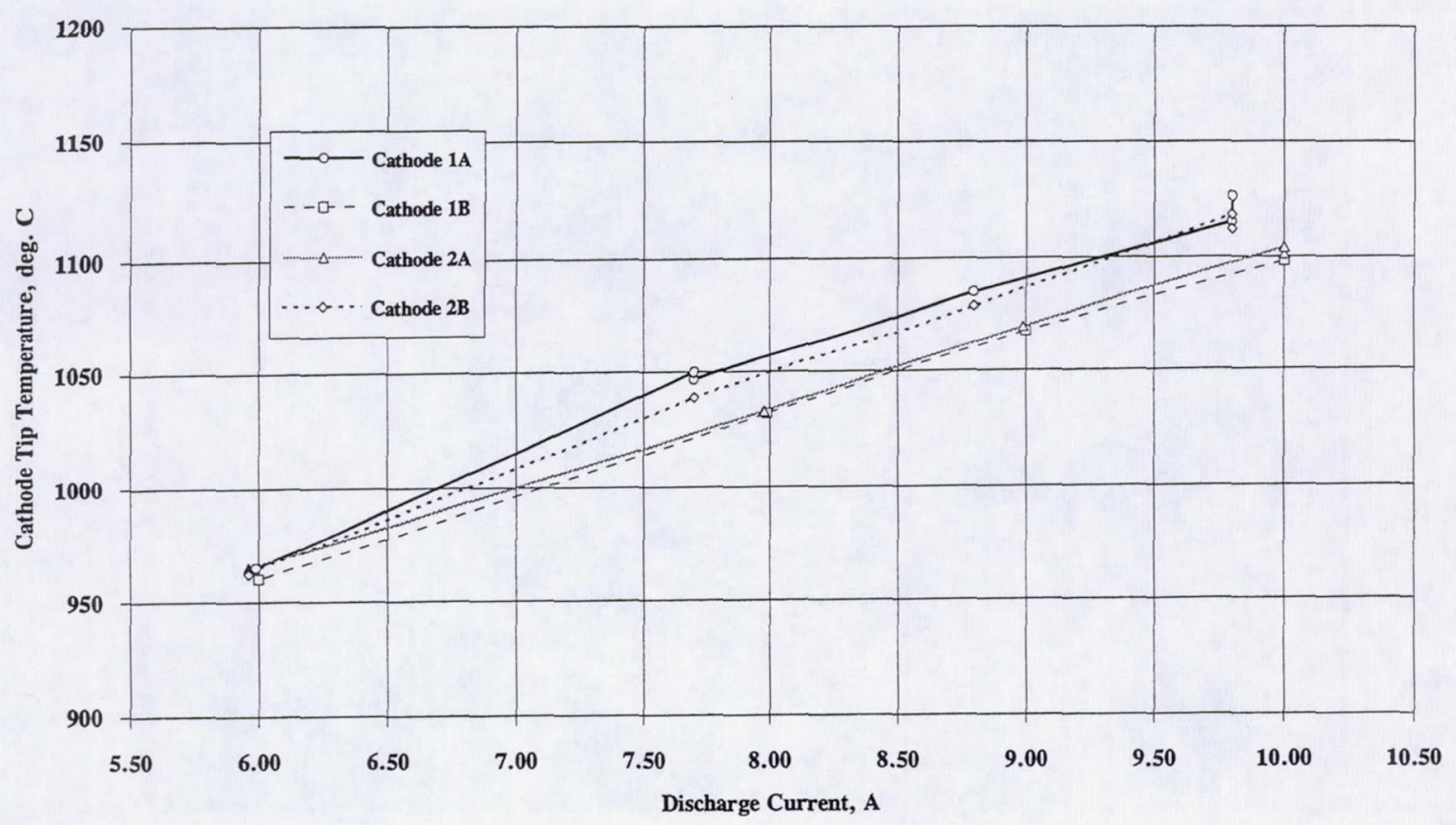

Fig. 13 Pre-test current-temperature characteristics for all cathodes at $0.9 \mathrm{mg} / \mathrm{s}$ except at $6 \mathrm{~A}$ where the flow is $1.0 \mathrm{mg} / \mathrm{s}$.

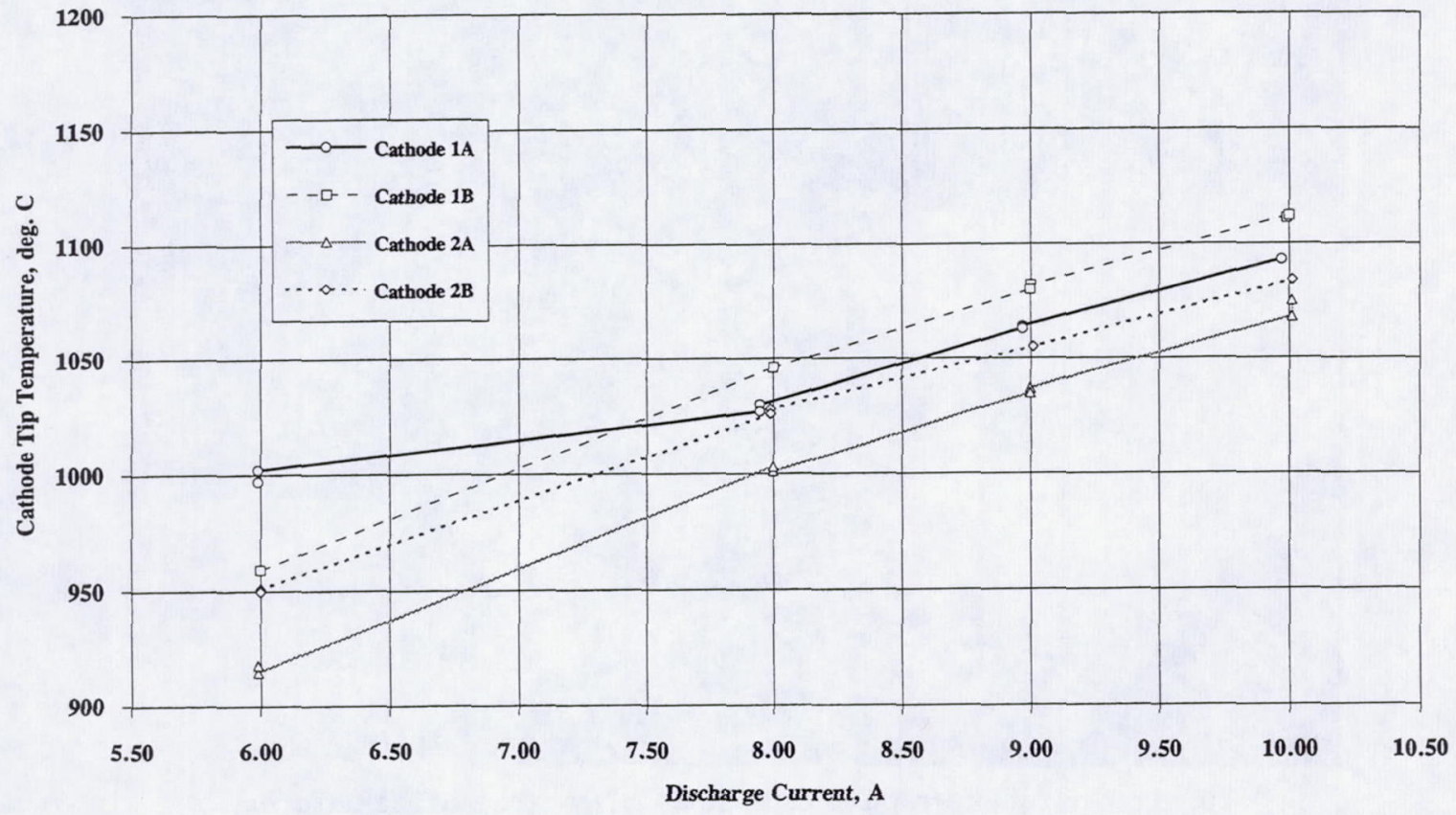

Fig. 14 Post-test current-temperature characteristics for all cathodes at $0.9 \mathrm{mg} / \mathrm{s}$ except at $6 \mathrm{~A}$ where the flow is $1.0 \mathrm{mg} / \mathrm{s}$. 


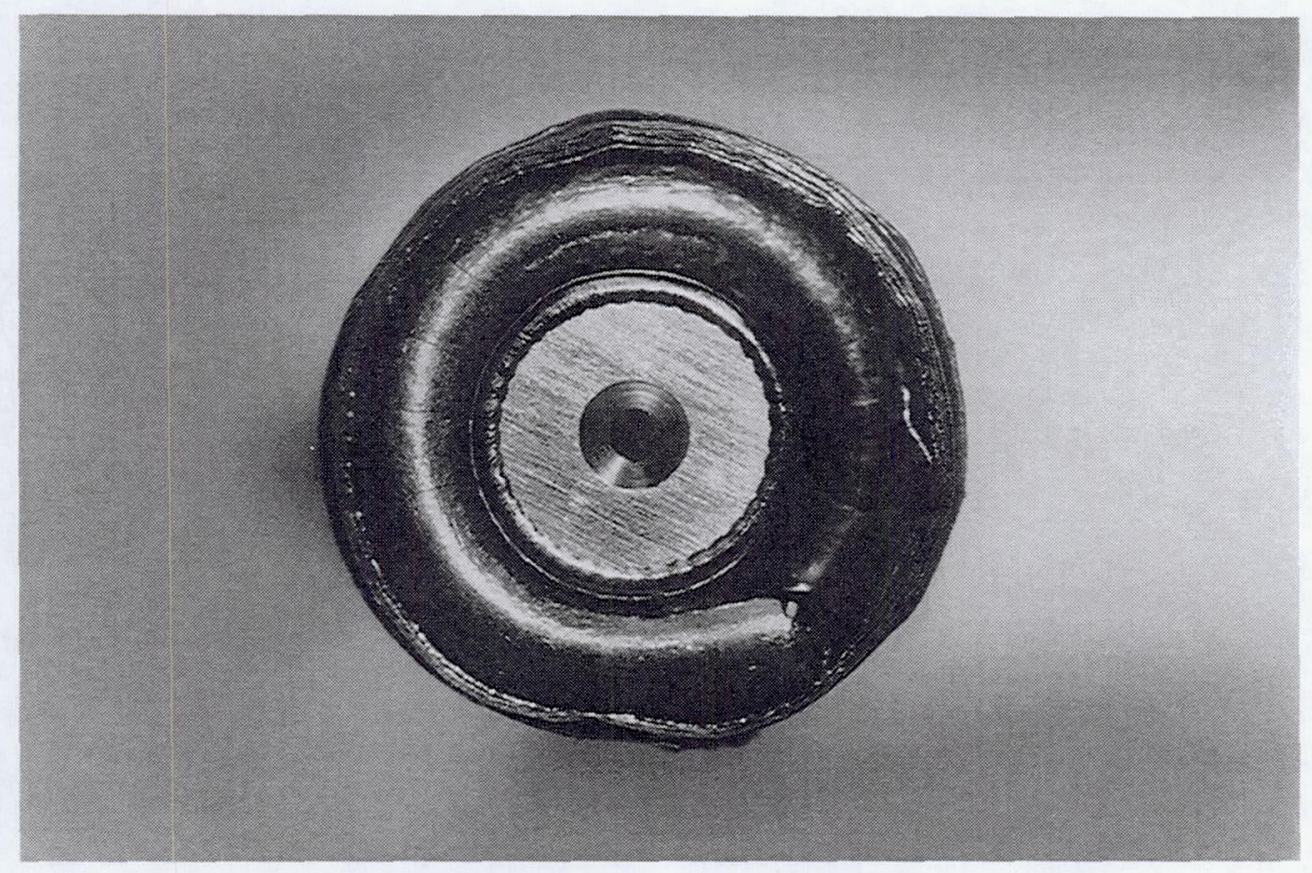

a. Pre-test photograph of cathode $2 \mathrm{~A}$. Note the machining marks on the orifice plate surface and chamfer.

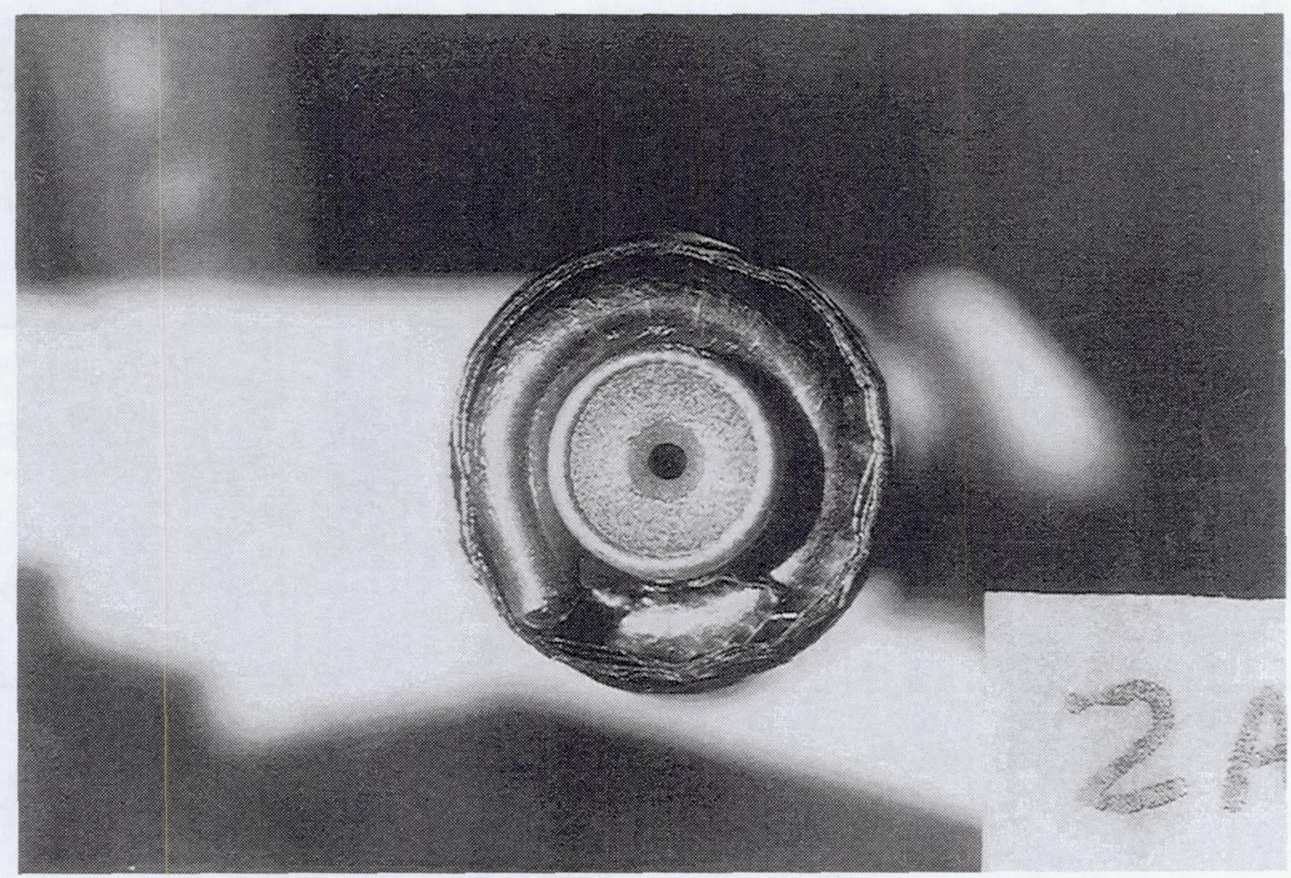

b. Post-test photograph of cathode $2 \mathrm{~A}$. Note the surface texturing of the orifice plate, especially in the chamfer.

Fig. 15 Pre- and post-test photographs of cathode $2 \mathrm{~A}$ orifice plate. 
Public reporting burden for this collection of information is estimated to average 1 hour per response, including the time for reviewing instructions, searching existing data sources, gathering and maintaining the data needed, and completing and reviewing the collection of information. Send comments regarding this burden estimate or any other aspect of this collection of information, including suggestions for reducing this burden, to Washington Headquarters Services, Directorate for Information Operations and Reports, 1215 Jefferson Davis Highway, Suite 1204, Arlington, VA 22202-4302, and to the Office of Management and Budget, Paperwork Reduction Project (0704-0188), Washington, DC 20503.

\begin{tabular}{|l|l|l|}
\hline 1. AGENCY USE ONLY (Leave blank) & $\begin{array}{r}\text { 2. REPORT DATE } \\
\text { July } 1994\end{array}$ & $\begin{array}{r}\text { 3. REPORT TYPE AND DATES COVERED } \\
\text { Final Contractor Report }\end{array}$ \\
\hline
\end{tabular}

4. TITLE AND SUBTITLE

Multiple Hollow Cathode Wear Testing for the Space Station Plasma Contactor

6. AUTHOR(S)

George C. Soulas

7. PERFORMING ORGANIZATION NAME(S) AND ADDRESS(ES)

NYMA, Inc.

Engineering Services Division

2001 Aerospace Parkway

Brook Park, Ohio 44142

9. SPONSORING/MONITORING AGENCY NAME(S) AND ADDRESS(ES)

National Aeronautics and Space Administration

Lewis Research Center

Cleveland, Ohio 44135-3191
5. FUNDING NUMBERS

WU-474-46-10

C-NAS3-25266

8. PERFORMING ORGANIZATION

REPORT NUMBER

E-9022

10. SPONSORING/MONITORING AGENCY REPORT NUMBER

NASA CR-195357

AIAA-94-3310

11. SUPPLEMENTARY NOTES

Prepared for the 30th Joint Propulsion Conference cosponsored by AIAA, ASME, SAE, and ASEE, Indianapolis, Indiana, June 27-29, 1994. Project Manager, Michael J. Patterson, Space Propulsion Technology Division, NASA Lewis Research Center, organization code 5330, (216) 433-7481.

\begin{tabular}{|l|l|}
\hline 12a. DISTRIBUTION/AVAILABILITY STATEMENT & 12b. DISTRIBUTION CODE
\end{tabular}

Unclassified - Unlimited

Subject Category 20

13. ABSTRACT (Maximum 200 words)

A wear test of four hollow cathodes was conducted to resolve issues associated with the Space Station plasma contactor. The objectives of this test were to evaluate unit-to-unit dispersions, verify the transportability of contamination control protocols developed by the project, and to evaluate cathode contamination control and activation procedures to enable simplification of the gas feed system and heater power processor. These objectives were achieved by wear testing four cathodes concurrently to 2000 hours. Test results showed maximum unit-to-unit deviations for discharge voltages and cathode tip temperatures to be $\pm 3 \%$ and $\pm 2 \%$, respectively, of the nominal values. Cathodes utilizing contamination control procedures known to increase cathode lifetime showed no trends in their monitored parameters that would indicate a possible failure, dernonstrating that contamination control procedures had been successfully transferred. Comparisons of cathodes utilizing and not utilizing a purifier or simplified activation procedure showed similar behavior during wear testing and pre- and post-test performance characterizations. This behavior indicates that use of simplified cathode systems and procedures are consistent with long cathode lifetimes.

14. SUBJECT TERMS

Hollow cathode; Plasma contactor; Ion thruster 20

16. PRICE CODE

$\mathrm{A} 03$

\begin{tabular}{|c|c|}
\hline $\begin{array}{c}\text { 17. SECURITY CLASSIFICATION } \\
\text { OF REPORT }\end{array}$ & $\begin{array}{c}\text { 18. SECURITY CLASSIFICATION } \\
\text { OF THIS PAGE } \\
\text { Unclassified }\end{array}$ \\
Unclassified
\end{tabular}

19. SECURITY CLASSIFICATION OF ABSTRACT Unclassified 